\title{
SMART THERMAL SEPARATOR: ADVANCED HOT-WATER ENERGY STORAGE USING AN ACTIVELY CONTROLLED INSULATING DISK
}

\author{
Jay M. Gite, Tom Butcher ${ }^{1}$, Rebecca Trojanowski ${ }^{1}$, Jon P. Longtin ${ }^{2}$ \\ ${ }^{1}$ Brookhaven National Laboratory, Upton, NY 11793, USA \\ ${ }^{2}$ Stony Brook University, Stony Brook, NY 11790, USA
}

\begin{abstract}
Thermal energy storage (TES) will play a vital role in the transition to renewable and non-traditional residential heating. The thermal output of biomass/wood, solar (thermal and PV), and geothermal heating systems, for example, can differ dramatically from a home's hourly heat demand, and thus benefit significantly from thermal storage. Traditional hot-water systems require either two separate tanks, which doubles the storage footprint and cost, or a single thermo-cline tank in which hot water resides in the upper region and cold water below. This design however has several short comings which limit the extent of its use. This study introduces the smart thermal separator (STS). The idea is to incorporate a movable, insulated, rigid disk (STS) inside a water storage tank to physically separate the hot- and cold-water regions. The vertical location of the disk between the hot- and coldwater regions is actively maintained using temperature sensors, a gyroscope, a pressure transducer and adjustable buoyancy control. The technical scope of the project includes a combined numerical and experimental development of a working prototype. A 190-liter or 50-gallon prototype is modeled and tested to assess the heat transfer and fluid flow in the system. This paper also demonstrates sizing of the STS for integration with a Biomass/Woodstove Powered Absorption Heat Pump System.
\end{abstract}

KEY WORDS: Thermal Energy, Renewable, Thermal Storage, Smart Thermal Separator, Stratification Efficiency, Absorption Heat Pump

\section{INTRODUCTION}

There is a consensus towards adoption of Renewable Energy as a way forward towards Sustainable Development. Thermal Energy Storage (TES) is both environmentally as well as economically vital. It is especially important in bridging the gap between availability of energy and its demand. Efficient thermal storage allows offsetting heat pump, electric heat, and $\mathrm{A} / \mathrm{C}$ run times to reduce peak load, thus helping to achieve the goal of reducing peak loads. Ground-source heat pumps, specifically, would benefit from thermal storage as this technology has the potential to solve some of the challenges associated with the complexity of ground piping loop and degradation of ground temperature (reduction in system COP) that current groundsource heat pumps face that are restricting the widespread use of this renewable energy source. Absorption Heat Pump Systems which use heat as the driving energy source will benefit greatly if coupled with efficient thermal storage unit as it will extend the spectrum of its adoption even when there are discrepancies in heat energy supply and demand. TES can also allow the use of Solar Energy, or Wood/Biomass Stoves as primary sources of energy to drive an Absorption Heat Pump Unit making it a Renewable Energy System. Even traditional gas- and oil-fired appliances benefit nominally from thermal storage, by allowing for optimal cycling times and minimizing short-cycling. Currently, however, thermal storage remains only sporadically used, due to the large size and space requirements of traditional tanks, restrictions on tank water withdrawal rates, which often result in oversizing, and high tank costs, due to the internal baffling requirement. 
Heating water for thermal storage is effective, safe, and low-cost. Traditional hot-water systems require either two separate tanks, which doubles the storage footprint and cost, or a single thermocline tank in which hot water resides in the upper region and cold water below. While reducing space, there are several disadvantages to the latter: i) Water must carefully added/removed to the tank, ii) The tanks must incorporate complex baffling components, diffuser enhancements [1] which then become customized, expensive components, and iii) The withdraw rates are restricted, all to avoid disturbing the delicate stratified temperature profile [2] in the tank. Also, even if undisturbed, the temperature profile will degrade over time, because the hot and cold water are in physical contact with each other. This factor becomes especially prominent when the temperature difference between the hot and cold-water regions increases giving rise to higher convective and advective currents which act as a catalyst to further increase the temperature difference leading to a thermal run-away. The STS introduced in this paper has the ability to overcome these shortcomings and promote extensive use of TES systems due to the following benefits: (1) It minimizes energy transfer by convection, conduction, and radiation from the hot- to the cold-water regions, allowing for better preservation of the desired hot (or chilled) water temperature and longer storage times. (2) The traditional problems associated with mixing and churning when water is added or removed are avoided, thus eliminating the need for interior baffling. (3) Tanks with much larger cross-sectional area and lower heights can be used thus making TES more feasible for domestic adoption. The STS system provides the previously unavailable opportunity to incorporate virtually any size or aspect-ratio tank, including wide, shallow tanks that can be built into the building structure. The tank can be fabricated on-site, e.g., in a basement, and can be rectangular or any arbitrary shape, while also being short and shallow.

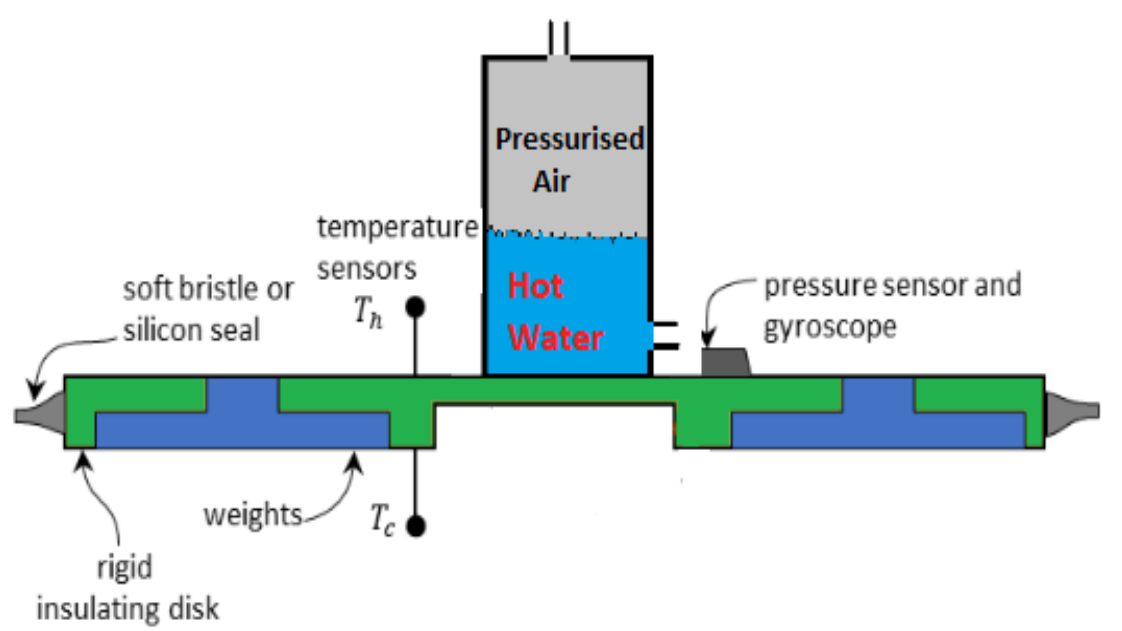

Fig. 1 Smart Thermal Separator (STS)

1.1 Smart Thermal Separator (STS) Referring to Fig. 1, Smart Thermal Separator (STS) is essentially a 20 to $30 \mathrm{~mm}$ thick disk and will incorporate metal, cement or stone ballast weights strategically located to maintain near-neutral buoyancy and a stable center of mass. The STS will sit in between the hot- and coldwater regions and thus act as a physical barrier between the two regions. A soft bristle or silicone wipe seal at the disk periphery minimizes water exchange between the hot- and cold tank regions. The disk is made with an insulating, closed-cell material, such as polyurethane $\left(120^{\circ} \mathrm{C} \max \right)$ or polyisocyanurate $\left(150{ }^{\circ} \mathrm{C} \max \right)$, as they have the required service temperature, are rigid, and can be expanded into pre-formed, moulded enclosures. Both materials have a density of $\sim 50 \mathrm{~kg} / \mathrm{m} 3$ and a thermal conductivity of $0.03 \mathrm{~W} / \mathrm{m}-\mathrm{K}$. Carbonfibre reinforcement rods $\left(300^{\circ} \mathrm{C}\right.$ max) can be used for large-area disks to maintain rigidity in the tank. It also consists of a Buoyancy Control Device to actively maintain the position of STS. The buoyancy control device will consist of a small inverted cylinder that will sit on top of the STS disk. Buoyancy control is to be achieved by moving air in and out of the cylinder (air pocket), which will result in a corresponding change in buoyancy. The required displaced volume of the BCD is small $(25 \sim 50 \mathrm{~cm} 3)$, since the density of water changes slowly with temperature, and the disk will be designed to be near-neutrally buoyant when initially fabricated. A low- 
cost pressure sensor will report the vertical location of the disk in the tank, based on the hydrostatic pressure. As an added advantage, the pressure sensor doubles as a 'fuel gauge' to indicate the reserve thermal capacity of the tank that can be provided to an advanced controls system. A gyroscope will ensure the disk is oriented correctly. A small umbilical tube/cable will be routed through the cold side of the tank to retrieve sensor data and adjust the buoyancy as needed. The unique active control approach with modern-sensor based control of STS presented in this paper overcomes the lacunas of traditional single-tank thermal storage which rely on naturally occurring thermocline.

\section{NUMERICAL SIMULATION RESULTS}

CFD Simulations have been performed to determine thermal losses and resulting temperature and thermocline degradation in traditional thermal storage devices and compare them to the STS technology proposed in this paper. The tank is initially maintained at a temperature of $311 \mathrm{~K}$. Hot water at $333 \mathrm{~K}$ is then introduced into the tank at a flow rate of $\mathrm{C} / 5$ per hour (C: Capacity of tank). A traditional single-tank thermocline storage system shown after 2.5 hours. As can be seen in Fig. 2, there is no separation between the hot-cold regions. As a result, there is diffusion and mixing of the water at the interface layer that degrades the thermal separation in the tank. The same tank configuration with the STS (thermal separator) after a same time period and similar inlet hot water conditions retains the thermal profile.
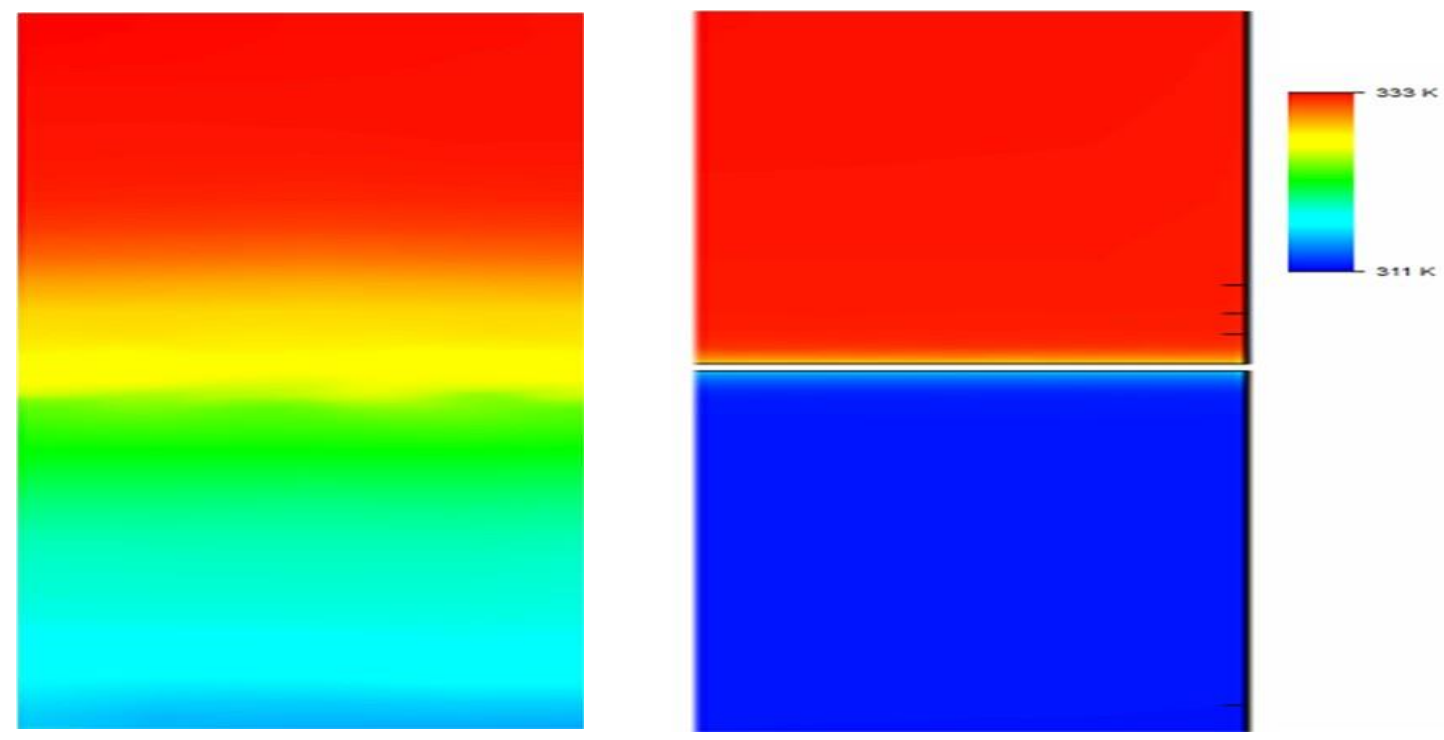

Fig. 2 CFD Simulation of STS Concept.

As noted earlier [2], the major factors contributing to degradation of thermocline region and corresponding loss of thermal energy (storage efficiency) are fluid mixing due to eddy currents, convective heat transfer, and heat lost to the surrounding. Convective currents are created within the tank due to the vertical temperature gradient along the tank wall, which cause mixing of hot and cold fluid in the region of the interface near the wall and are responsible for a significant amount of the degradation in this case. Flow into and out of the tank at the hot and cold ports also contributes to the establishment of convective current circulation which in turn speeds up thermocline degradation. Studies [1,2] have reported that convective currents and the resulting fluid mixing is a much more important factor influencing the thermocline degradation. Fig. 3 shows the fluid motion (currents) around the thermocline region in traditional thermal storage tanks which is primarily responsible for degradation of thermal profile. A fine mesh grid has been developed near the thermocline region to accurately capture the fluid behavior near the thermocline. 


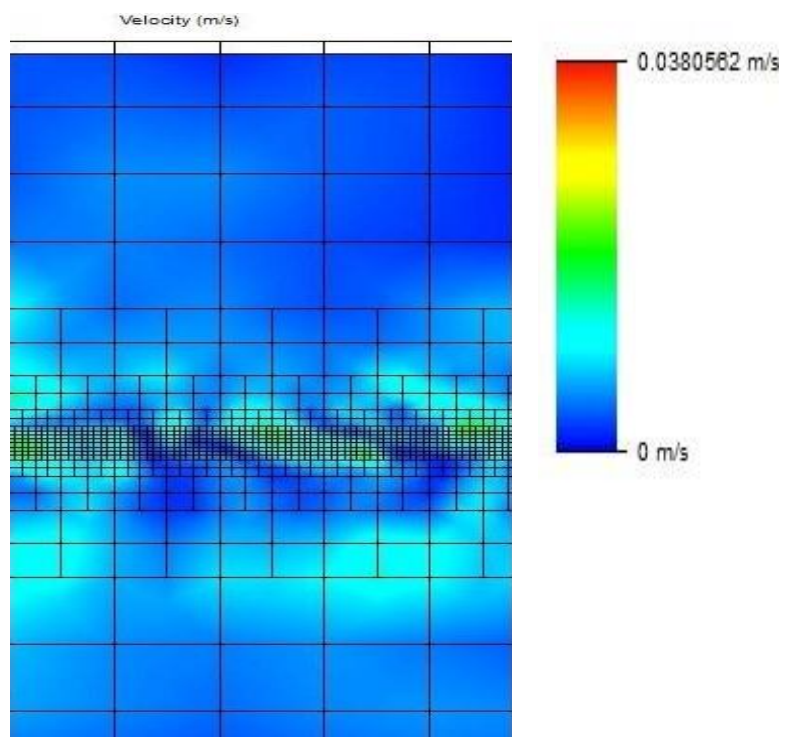

Fig. 3 Fluid Motion (Currents) near the Thermocline Region.

Within the scope of STS technology, heat lost to environment is negligible [3] due to the use of high-quality insulation which can completely isolate the wall tanks from the surrounding for a cycle time-period typical for Thermal Energy Storage systems. There is a possibility of having small convective currents being setup on either side of the STS disk due to conductive nature of tank wall inner lining. However, due to the novel concept of having an actively controlled barrier (STS disk) separating the hot- and cold-water regions, fluid mixing due to these convective currents and eddy currents does not occur. Thermal diffusion between the hot- and cold-water regions is also brought down to negligible levels owing to the insulative properties of the STS disk.

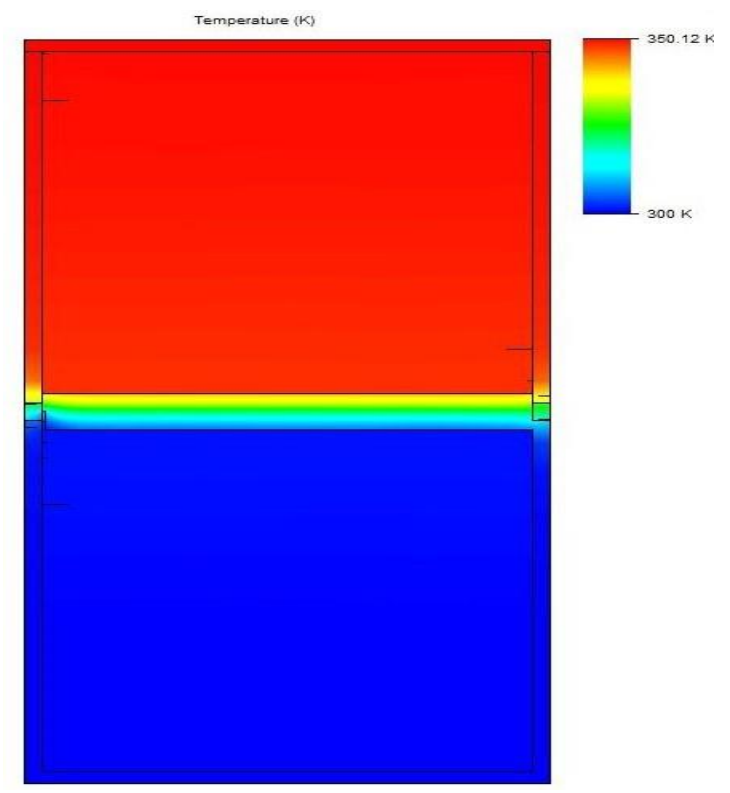

Fig. 4 CFD Simulation of STS for 24-hours.

STS thermal storage system can store heat with minimal temperature degradation (thermal losses) for longer time intervals and thus has the potential to remain in a charged state for longer time than traditional thermal storage tanks. A 24-hour simulation has been performed on a tank with STS and results obtained are as shown in Fig. 4. The tank is initially maintained at $300 \mathrm{~K}$ and then hot water is introduced at a temperature of around $350 \mathrm{~K}$ at a flow rate of $\mathrm{C} / 5$ per hour ( $\mathrm{C}$ : Capacity of tank). As can be seen, the thermal profile has been maintained even for 
such long duration. The results show that the STS system can perform space heating (cooling) operation without the need for charging even for longer durations of time. This ability is particularly attractive for thermal storage of solar energy [4] which can remain unavailable for longer period.

\section{INTEGRATION OF STS WITH BIOMASS/WOODSTOVE POWERED ABSORPTION SYSTEM}

3.1 Concept and Motivation Studies [5,6] have indicated that the heat release (burning) profile of wood stove is very different from the energy requirement of a typical house. As can be seen in Fig. 5, the energy demands of house remain at a constant value for considerable amount of times (1.5-3 hours). However, the wood burning profile shows that the energy output from wood follows a constantly varying pattern. Also, the drop-in energy requirement of house is very steep once we pass the peak requirement phase of around 1.5 hours. However, the heat release rate of wood stove drops over a wide range of time. This problem (overheating of house) can also be resolved with TES by storing the excess thermal energy, thus improving the efficiency. For a wood stove, there is some amount of delay between the time the wood starts burning and when it has its peak energy release rate. This delay is typically around 1-1.25 hours. This means that the wood stove needs to be made operational at least an hour before peak load requirements. This can be troublesome since the peak load requirements for a typical house are around early morning. Also, the space heating requirements increase drastically from steady state condition during peak load hours. To meet this demand, the heating system needs to be capable of delivering the required heat output with minimum delay time. For the case considered in [5], the heating capacity of the system needs to be increased by $77 \%$ and $183 \%$ of the steady state condition (fixed set temperature) during peak load hours if the multiple-step and single-step thermostat schemes are chosen respectively. Intermittent energy sources (solar, wood) cannot assure to meet these increased demands during peak load hours. However, with TES, the energy from these intermittent sources can be stored during off-peak hours (supply>demand) and used during peak load hours to meet the increased energy demand. The average energy demand, whether we choose single stage or multistage thermostat control also depends on the floor area under consideration. Thus, even if we decide type of thermostat control that we want, energy input required will fluctuate as area under consideration changes. This issue can be resolved with TES which can adjust the energy release rate accordingly to deliver the energy requirements as per the area under consideration and store the excess heat energy. This feature of TES can make partial house heating possible if required.

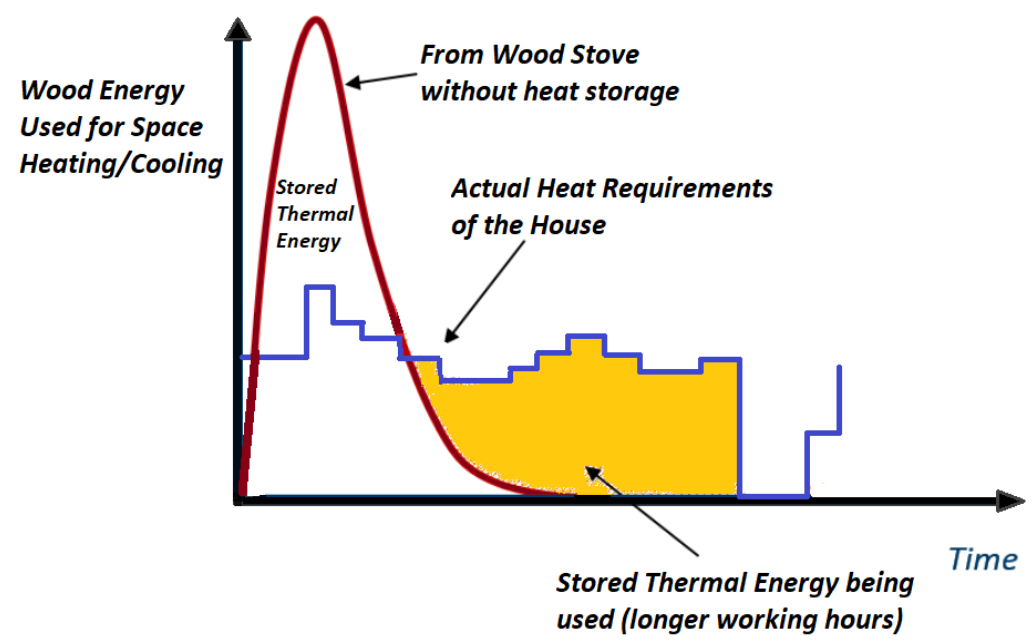

Fig. 5 Wood Burning Profile compared to Typical House Space Heating Requirements.

Absorption system can be used in heating mode as well as cooling mode. When used in heating mode, the supply temperature required to run the system with maximum COP is around $120^{\circ} \mathrm{C}$ and for cooling mode it is around $90^{\circ} \mathrm{C}$. However, typical woodstoves have burning temperatures higher than these and the quantity of burning wood feed cannot be altered once the stove has been activated. In order to have a constant supply temperature to 
the absorption system, the idea is to regulate the flow rate of water through the woodstove such that its delivery temperature is maintained at the desired temperature value. However, the required flow rate of input water to the absorption system is constant and it depends upon the space heating requirements and outside air temperatures. During most of the times, the flow rate of water through the stove is higher than the flow rate of water required by the absorption system. The concept of STS combined with biomass/woodstove powered absorption system is to make the space heating and cooling processes energy efficient by storing the excess heat contained in the water flowing through the woodstove. The system has the potential to meet the space heating and cooling requirements in the most energy efficient manner making it both environmentally as well as economically viable.

3.2 Sizing of STS Energy Storage System The schematic layout of STS system coupled to a biomass/woodstove unit is as shown in Fig. 6. A PID based control mechanism using Variable Frequency Drives can be implemented to control the flow rate of water throughout the system. The COP of absorption system comes out to be around 1.55 and the thermal storage tank size required is around 6050 liters (1600 gallons) under following considerations:

- $\mathrm{Q}_{\text {house }}=22 \mathrm{KW}$ or $75000 \mathrm{BTU} / \mathrm{hr}$

- $\quad$ Space Heating Area $=2500$ to $2700 \mathrm{sq}-\mathrm{ft}$

- TES independent working hours $=12$ to 14 hours

- Generator Temperature $=80$ to $85^{\circ} \mathrm{C}$

- Absorber Temperature $=20$ to $25^{\circ} \mathrm{C}$

- Outside Air Temperature $=-7$ to $-10^{\circ} \mathrm{C}$

- $\quad$ Defrosting Considered $=$ Yes

- Generator Inlet Water Temperature $=120$ to $125^{\circ} \mathrm{C}$

- Generator Outlet Water Temperature $=90$ to $95^{\circ} \mathrm{C}$

- Generator (Heat Exchanger) Effectiveness $=0.85$ to 0.87

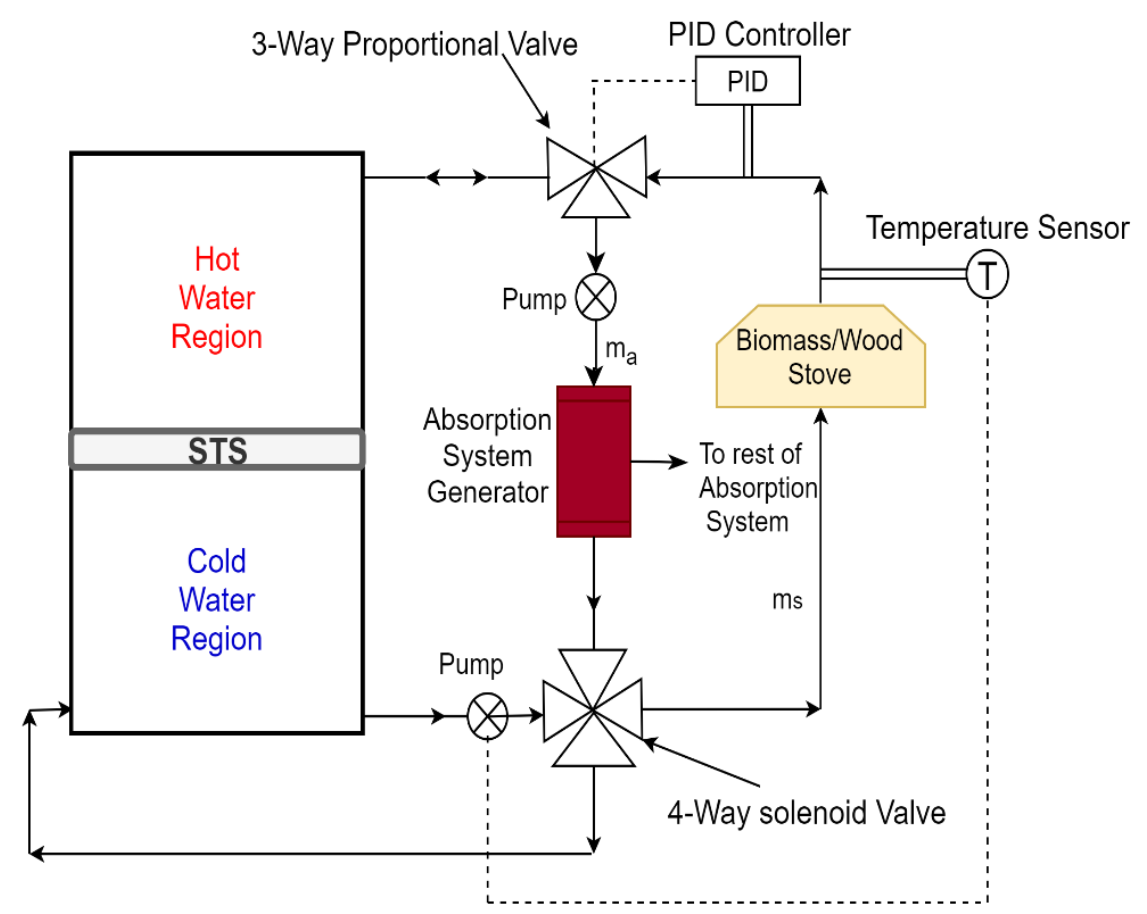

Fig. 6 STS combined with Biomass/Woodstove Powered Absorption System Schematic Layout.

The heat energy required to drive the absorption system comes from the hot water at the inlet of generator. The equation for the heat energy the hot water must carry to drive the system can be written as:

$$
Q_{\text {hot-water }}=\frac{Q_{\text {house }}}{\operatorname{COP}} \times 1 \cdot 13
$$


The equation for heat energy extracted from hot water is given by:

$$
Q_{\text {hot-water }}=\dot{m} \times C_{P} \times \Delta T_{\text {water }}
$$

Using these two equations, it is possible to determine the size of STS storage tank to power the system.

There will be 3 operational modes for the combined system:

- Absorption Unit Active Only - During this phase, the stove is kept non-operational and only the absorption unit is running. Hot water from the already charged STS storage tank is drawn in by the absorption system and cold water is discharged out which is again fed back to the cold-water side of the STS tank.

- Absorption + Stove Unit Active - During this phase, both absorption unit as well as the stove unit is running. Under this working condition, the tank can either charge, discharge or remain inactive depending the mass flow rate of water through the stove and the mass flow rate of water required by the absorption system. If, i) $\mathrm{m}_{\mathrm{a}}=\mathrm{m}_{\mathrm{s}}$ (no draw from tank); ii) $\mathrm{m}_{\mathrm{a}}<\mathrm{m}_{\mathrm{s}}$ (tank charges); iii) $\mathrm{m}_{\mathrm{a}}>\mathrm{m}_{\mathrm{s}}$ (tank discharges).

- Stove Unit Active Only - During this phase, the absorption system is inactive and only the stove unit is running. Thus, the tank charges during this mode of operation.

STS Technology can also benefit other intermittent forms of energy sources apart from biomass/wood. A summary of how each heating technology could benefit from the STS technology is shown in Table 1 below.

Table 1 Summary of heating technologies and the role STS can play.

\begin{tabular}{|c|c|c|}
\hline Technology & Issue/Need & Role of Smart Thermal Storage \\
\hline $\begin{array}{c}\text { Biomass / } \\
\text { Woodstoves }\end{array}$ & $\begin{array}{l}\text { Thermal output not well matched } \\
\text { to typical building load }\end{array}$ & $\begin{array}{c}\text { Store excess heat when not } \\
\text { needed; and deliver provide } \\
\text { heating or cooling between output }\end{array}$ \\
\hline $\begin{array}{l}\text { Geothermal / } \\
\text { Ground-Source } \\
\text { Heat Pumps }\end{array}$ & $\begin{array}{l}\text { Preferred operation when (a) } \\
\text { electricity is cheaper (night) and } \\
\text { (b) limited capacity to recover } \\
\text { setpoint temperature after } \\
\text { nighttime setback; Complexity of } \\
\text { ground loop piping increases as } \\
\text { the House Load increases; } \\
\text { Degradation of ground } \\
\text { temperature over a period, } \\
\text { resulting in reduced COP of the } \\
\text { system }\end{array}$ & $\begin{array}{l}\text { Pre-charge thermal storage when } \\
\text { electricity costs are low, or before } \\
\text { nighttime set-back; Allows the } \\
\text { ground loop piping design for } \\
\text { medium load (thus reducing the } \\
\text { complexity); Allows heat } \\
\text { extraction process to be slow and } \\
\text { uniform (helps to reduce the } \\
\text { temperature degradation of } \\
\text { ground) }\end{array}$ \\
\hline Solar-Thermal & $\begin{array}{c}\text { Intermittent heat availability } \\
\text { (day only, function of cloud cover) }\end{array}$ & $\begin{array}{l}\text { Provide thermal buffer for night- } \\
\text { time/cloudy days. }\end{array}$ \\
\hline Solar - PV & $\begin{array}{c}\text { Intermittent heat availability } \\
\text { (day only, function of cloud cover) }\end{array}$ & $\begin{array}{l}\text { Provide thermal buffer for night- } \\
\text { time/cloudy days }\end{array}$ \\
\hline Natural gas / oil & $\begin{array}{l}\text { Partial loads and frequency } \\
\text { cycling reduce device } \\
\text { efficiency; systems often } \\
\text { oversized to meet worst-case } \\
\text { building loads }\end{array}$ & $\begin{array}{l}\text { Reduce cycling; allow a smaller } \\
\text { capacity system to reduce costs } \\
\text { and increase efficiency }\end{array}$ \\
\hline $\begin{array}{l}\text { Electric Heat } \\
\text { Systems }\end{array}$ & Electricity is expensive & $\begin{array}{l}\text { Store energy at night, if cheaper } \\
\text { electric rates are available }\end{array}$ \\
\hline
\end{tabular}




\section{EXPERIMENTAL SETUP}

4.1 Concept A 50-gallon water storage tank shown in Fig. 7 has been selected for prototype development of the STS system. An air compressor coupled with an air control valve has been used to control the flow of air in and out of the buoyancy control element of the STS. A pair of solenoid valves is used which determine the direction of air flow which in turn depends on the average density that the STS needs to attain to main its position accurately between the hot and cold-water regions. The temperature sensors on either side of the STS disk measures the temperature of hot and cold-water regions respectively. The water density of hot as well as cold water regions is calculated and the average of the two densities is used as a target value for the buoyancy for the STS disk. Small density adjustments using pressurized air is then made to the air pocket to fine-tune the disk buoyancy. The STS system has the ability to have both passive control (adjust the buoyancy to the average of the hot- and cold-water densities, and then do no change) and active control (add air until disk starts to rise, then vent to cause it to sink). The latter is particularly useful when the water temperatures (in hot or cold or both regions) is changing with time, for e.g., towards the end of a biomass/wood stove fuel burn out.

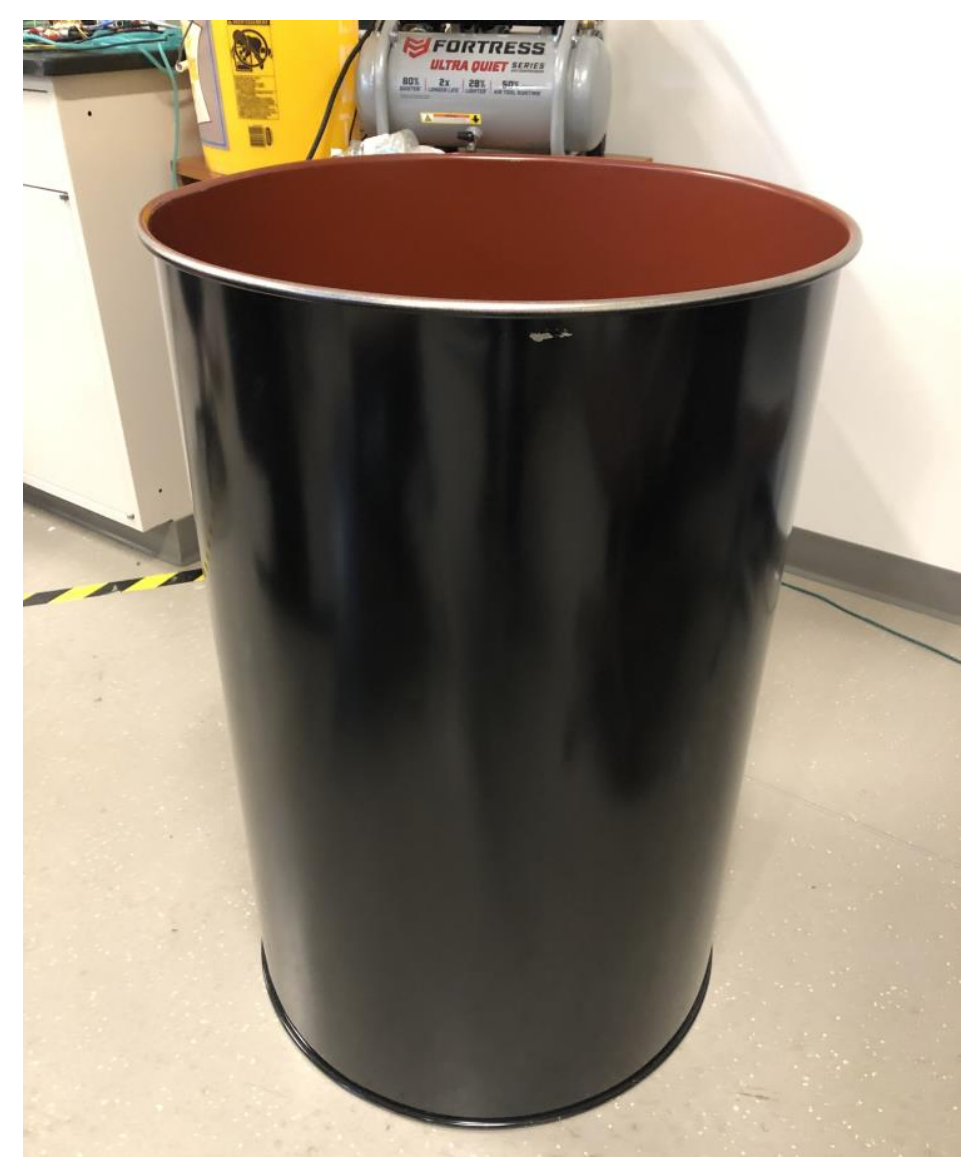

Fig. 7 Prototype Water Storage Tank

4.2 Control Mechanism A closed loop control mechanism has been developed to facilitate active and passive control of the STS disk. The control side of things consists of an ARDUINO Board coupled with a 16-bit ADC which acts as the central processing unit of the STS system. The 16-bit ADC provides an exceptionally high accuracy with regards to reading the data from the sensors. ADC reads data from the pressure and temperature sensors and sends the data to ARDUINO for processing. The ARDUINO drives the solenoid valves via a Relay Board. A 12 Volts power supply is provided to drive the solenoid valves through the Relay Shield. Data from 
pressure sensor is processed by ARDUINO to determine the position of STS disk in the tank. Fig. 8 Shows the plumbing connections and control mechanism deployed.

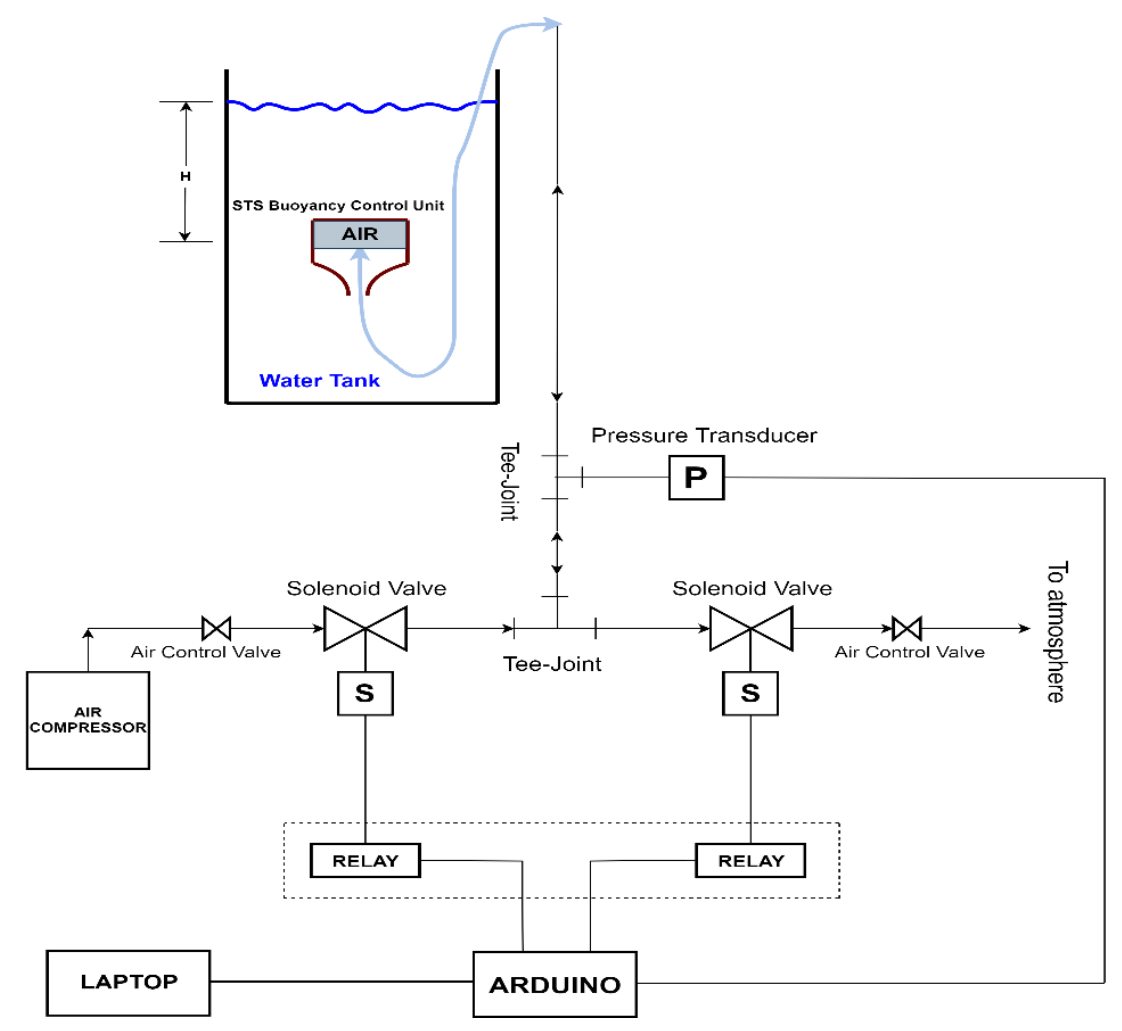

Fig. 8 Plumbing and Control Mechanism used in the Smart Thermal Separator (STS) System.

4.3 Concept Testing To test the concept of buoyancy control to actively control the STS disk, a small demo experiment was performed. A small inverted cylinder (buoyancy control unit) resembling the one to be placed on the STS disk was chosen for the experimentation. The aim of this experiment was to achieve neutral buoyancy at a pre-determined vertical level and make the cylinder stay at that level in a tank with water at a fixed temperature. Another objective was to have hot- and cold-water regions in the tank and actively control the density of cylinder such that it floats at the interface between the water regions having a temperature gradient. The cylinder attains equilibrium at a horizontal level when it becomes neutrally buoyant. To move the cylinder from one horizontal level to another, the equilibrium is disturbed by changing the density of the cylinder which is done by adding or removing compressed air from the air pocket in the cylinder. Pressure Transducer reports the position of the cylinder and the decision to add or remove the air is taken accordingly depending upon whether the cylinder is required to move up or down. To fine tune the flow rate of air into and out of the cylinder, air control valves are used on delivery and vent side of the plumbing.

4.4 Prototype Model The prototype model consists of an acrylic (plastic) disk as shown in Fig. 9 which will be used as the physical separator (STS) between hot and cold fluid regions at this stage of the experimentation process. Three cylinders which act as the buoyancy control units are attached at the top of the disk. The cylinders are strategically located to ensure the stable equilibrium of the disk as can be seen in Fig. 10. The cylinders are internally connected to each other to ensure that equal volume of compressed air is delivered to each cylinder when the inlet solenoid valve is operated. The fact that the cylinders are connected to each other also ensures that the air pressure is the same in all the cylinders. This prototype also has temperature sensors attached to the top and bottom of the STS (disk). These sensors read the water temperatures in the hot and cold fluid regions and with that data, the densities of the two regions is determined which is then used to determine the density required by the STS unit for it to float between the two regions. The STS unit with the active buoyancy control feature is able to park itself at the thermocline (interface) between the hot and cold fluid regions. The prototype model has both manual as well as automatic control features. The STS prototype model 
is potentially able to retain the thermal profile and thus store thermal energy for longer durations of time due to the presence of a physical barrier between the hot-and cold fluid regions.

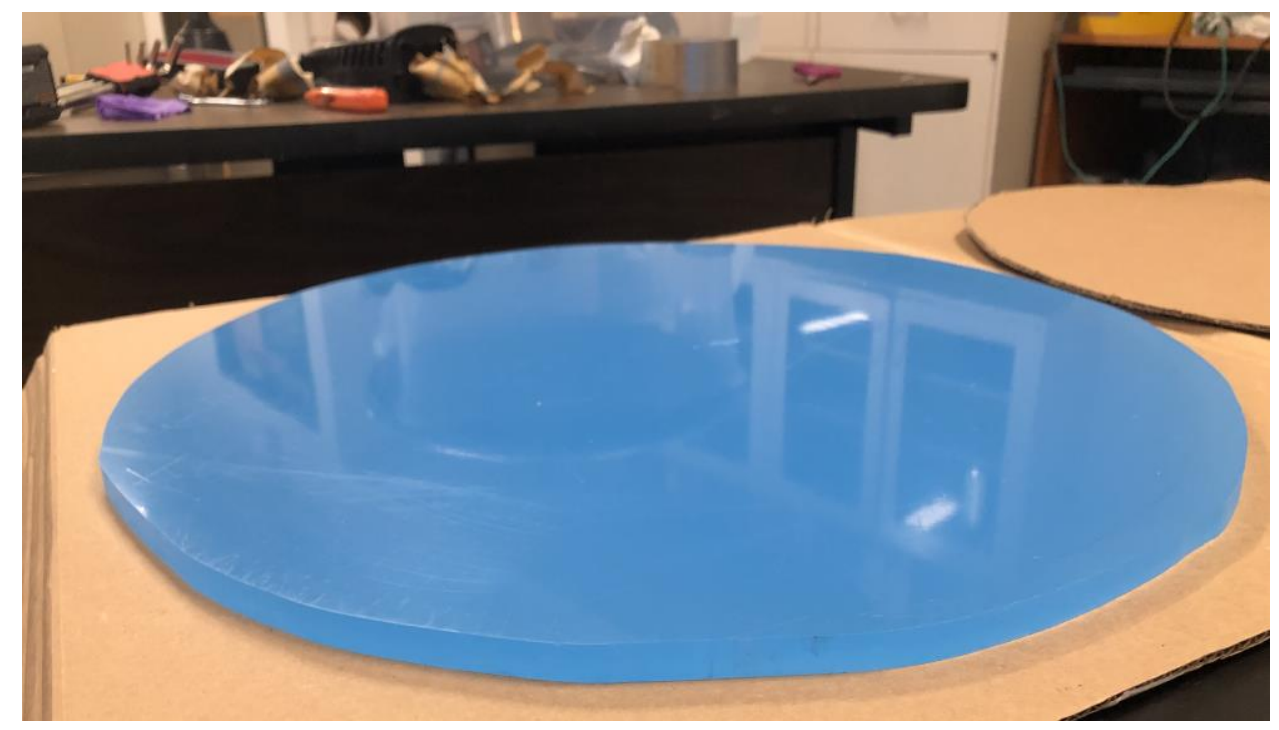

Fig. 9 Acrylic Disk (Prototype STS)

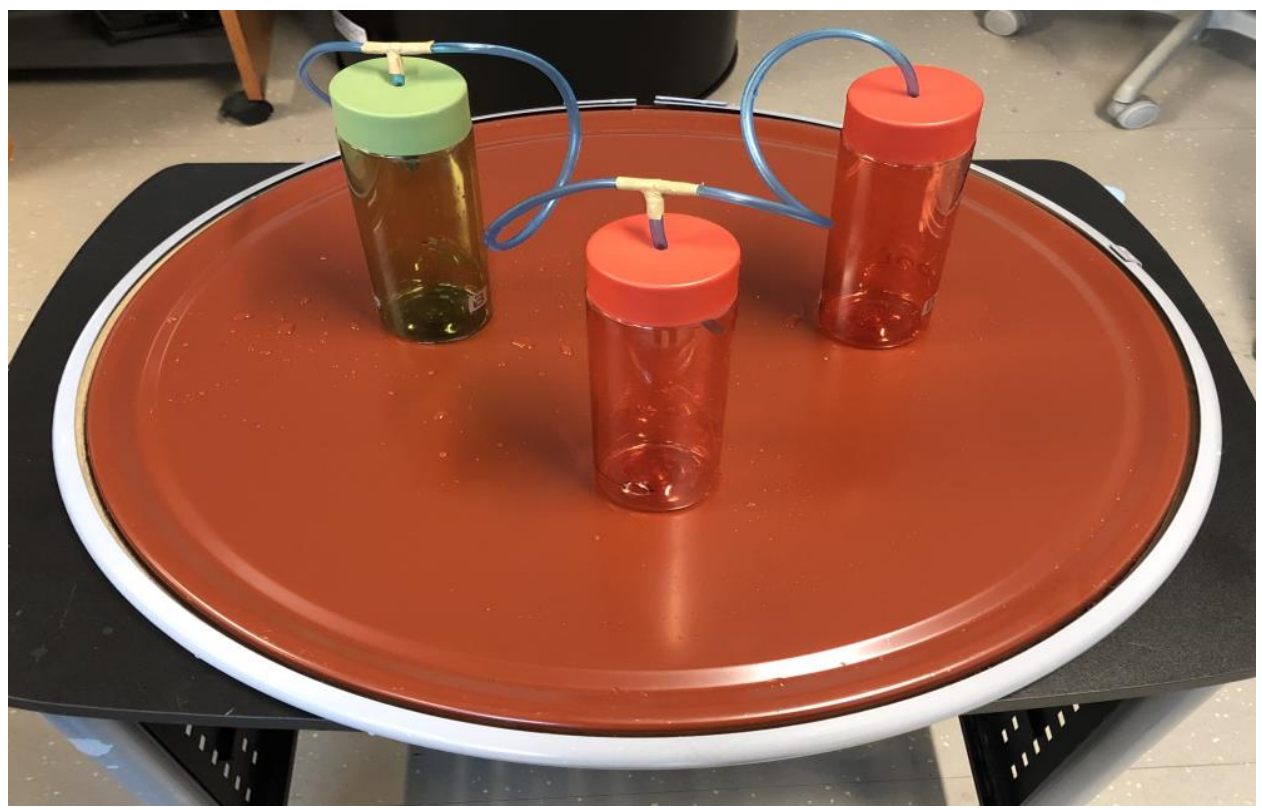

Fig. 10 STS Buoyancy Unit

\section{CONCLUSIONS AND FUTURE WORKS}

The novel concept of STS thermal energy storage has an advantage of obtaining higher energy output due to reduced thermal losses. The STS system represents a means to improve efficiency, reduce complexities and provide more uniform comfort with a variety of heating systems. This system has the potential to develop into a low-cost, flexible thermal energy storage system that can be easily implemented in residential homes and industries to provide improved cycling efficiency for a variety of different heating (and cooling) technologies. A general Literature review and market survey allowed us to determine the underlying factors behind lack of market penetration for thermal energy storage systems especially for residential applications. The concept of 
STS thermal storage system has been developed with a view to resolve these problems and make thermal energy storage more viable. The technology also has an added advantage of being essentially heatingequipment blind, in that it can provide a benefit to a wide range of heating systems, albeit in different ways and with different benefits. Results show that STS system can retain its thermal profile for wide range of temperature difference between hot and cold regions and for much longer times than the traditional thermocline based thermal storage systems making it an attractive option for thermal energy storage of intermittent renewable sources of energy like solar. This system has the potential to be further developed into a thermal battery with efficiencies significantly higher than its electrical counterparts. The combined approach of integrating STS energy storage unit with Biomass/Woodstove powered absorption heat pump system discussed in this paper can also be further investigated as it has the potential to completely revolutionize space heating and cooling for commercial as well as residential spaces.

\section{NOMENCLATURE}

$Q_{\text {house }} \quad$ Space Heating Requirement

ma Mass Flow Rate of water inlet to Absorption System

$(\mathrm{KW})$

ms Mass Flow Rate of water inlet to Wood/Biomass Stove

$\Delta T_{\omega} \quad$ Temperature difference of water between Inlet and Outlet of Generator

$(\mathrm{Kg} / \mathrm{sec})$

$(\mathrm{Kg} / \mathrm{sec})$

$\mathrm{COP}$

Coefficient of Performance for Absorption System

$(\mathrm{K})$

\section{REFERENCES}

[1] MS Shin, HS Kim, DS Jang, SN Lee, YS Lee, HG Yoon, "Numerical and experimental study on the design of a stratified thermal storage system,” Applied Thermal Engineering., vol. 24 Issue.1, pp. 17-27, (2004).

[2] Walmsley, Michael \& Atkins, Martin \& Riley, J.., "Thermocline Management of Stratified Tanks for Heat Storage," Chemical Engineering Transactions, vol. 18, (2009).

[3] Bymaikel Shaarawy, Numerical Analysis of Thermal Stratification in Large Horizontal Thermal Energy Storage Tank, MS. Thesis, McMaster University, (2014)

[4] Li, Z.F. \& Sumathy, K.., " Performance Study of a Partitioned Thermally Stratified Storage Tank in a Solar Powered Absorption," Applied Thermal Engineering., vol. 22., pp. 1207-1216, (2002).

[5] Tariku, F. \& Kumaran, M. \& Fazio, Paul., "Thermostat Setback Effect in Whole Building Performance," Building Physics Symposium., (2010).

[6] D.L. Chamberlain, Heat Release Rate Properties of Wood-Based Materials, 10 20, 2019, https://www.govinfo.gov/content/pkg/GOVPUB-C13-c36205f5e8205bd7183d3f63470ed813/pdf/GOVPUB-C13c36205f5e8205bd7183d3f63470ed813.pdf, (1983). 